\title{
RANCANG BANGUN SISTEM PENCAHAYAAN OTOMATIS BERBASIS PEMROGRAMAN LADDER PLC (PROGRAMMABLE LOGIC CONTROLLER) ZELIO
}

\author{
Andri Ferdiansyah ${ }^{1}$, Ida Bagus Alit Swamardika ${ }^{2}$, I Gusti Agung Putu Raka Agung ${ }^{3}$
}

\begin{abstract}
For efficiency of electrical energy consumption and safety reason, lighting source need to be controlled when building leaved by owner. It can be solved by build a lighting system that can be controlled automatically depend the time programmed and light intensity level at room. LDR (Light Dependent Resistor) and real time clock function at zelio used as input signal to activate the lamps. Zelio PLC (Programmable Logic Controller) is used to be main controller what processed all the input signals.

Intisari-Demi alasan efisiensi konsumsi energi listrik dan keamanan, sumber pencahayaan perlu dikontrol saat bangunan ditinggalkan oleh pemilik. Hal ini dapat diatasi dengan membuat sebuah sistem pencahayaan yang bisa dikontrol secara otomatis sesuai waktu yang diprogram dan tingkat kecerahan pada suatu ruangan. Fungsi real time clock pada PLC Zelio dan modul LDR (Light Dependent Resistor) digunakan sebagai sinyal masukan untuk menyalakan lampu. Kontroler utama yang digunakan adalah PLC Zelio yang digunakan untuk memproses semua sinyal masukan.
\end{abstract}

Kata Kunci-PLC, Zelio, LDR, real time clock.

\section{Pendahuluan}

Nyala lampu sebagai sumber pencahayaan perlu dikontrol saat bangunan ditinggalkan oleh pemilik. Selain demi alasan keamanan pada malam hari, pemakaian sumber pencahayaan pada siang hari atau saat kondisi terang perlu diatur demi efisiensi konsumsi energi listrik saat bangunan ditinggalkan.

Pada penelitian sebelumnya telah dirancang sistem pencahayaan otomatis menggunakan sensor LDR berbasis microcontroller . Pada penelitian ini tidak dilengkapi dengan masukan real time clock function untuk mengatur nyala lampu sesuai waktu yang diprogram [1].

Dari penelitian sebelumnya, maka akan dibuat rancang bangun sistem pencahayaan otomatis pada bangunan berbasis pemrograman ladder zelio. Penelitian ini diharapkan mampu mengatur nyala dan padamnya lampu berdasarkan waktu yang bisa diprogram pada diagram ladder memanfaatkan real time

${ }^{1}$ Mahasiswa, Jurusan Teknik Elektro dan Komputer Fakultas Teknik Universitas Udayana, Perum Nongsa Asri Blok C3 No.5 Batam - Kepulauan Riau 29465 INDONESIA (tlp: 085765143517; e-mail: andriyox@gmail.com)

${ }^{2}$ Dosen, Jurusan Teknik Elektro dan Komputer Fakultas Teknik Universitas Udayana, Jln.Pulau Seribu No.22 Denpasar 80237 INDONESIA (telp: 085237256257; e-mail: alit_bbc@yahoo.com)

${ }^{3}$ Dosen, Jurusan Teknik Elektro dan Komputer Fakultas Teknik Universitas Udayana, Br. Anggarkasih, Medahan, Blahbatuh, Gianyar 80581 INDONESIA (telp: 081999898301; e-mail: igapraka@yahoo.co.id)

Andri Ferdiansyah: Rancang Bangun Sistem Pencahayaan... clock function atau sesuai tingkat kecerahan pada suatu ruangan.

Selain itu, kontroler utama yang digunakan pada penelitian ini menggunakan PLC (Programmable Logic Controller) dengan keunggulan lebih fleksibel dan koreksi program yang lebih mudah [2].

\section{KAJIAN PUSTAKA}

\section{A. PLC (Programmable Logic Controller)}

National Electrical Manufacturers Association (NEMA) mendefinisikan PLC (Programmable Logic Controller) sebagai sebuah perangkat elektronik berbasis digital yang mempunyai memori yang bisa diprogram untuk mengolah fungsi fungsi spesial seperti logika, sekuensial, pewaktuan, penghitungan, dan komputasi sinyal masukan atau keluaran analog maupun digital yang dapat diterapkan untuk berbagai macam mesin dan proses produksi. "PLC (Programmable Logic Controller) menggantikan fungsi relay, timer, counter yang digunakan pada kontroler lama dengan komponen semikonduktor seperti IC (Integrated Circuit) dan transistor dengan tambahan kemampuan komputasi pada fungsi dasar pengontrolan untuk membuat kontrol yang bisa diprogram." (R\&D Center,2010:3) [3].

\section{B. Zelio SR2B121BD}

Zelio merupakan produk PLC (Programmable Logic Controller) yang diproduksi oleh Schneider Electric. Zelio pada sistem otomasi digunakan sebagai main controller yang memproses sinyal masukan untuk selanjutnya diteruskan ke perangkat keluaran. Zelio merupakan perangkat elektronik yang kompatibel untuk digunakan sebagai perangkat pemrograman mesin mesin ataupun perintah sederhana dalam industri. Gambar 1 merupakan perangkat keras zelio (SR2B121BD).

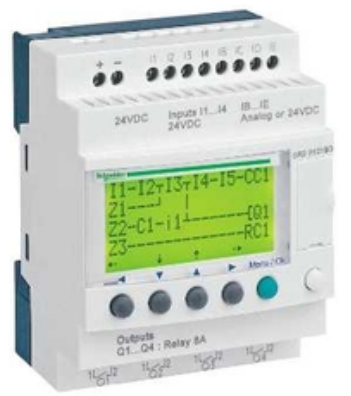

Gambar 1: Zelio SR2B121BD 
Zelio (SR2B121BD) mempunyai empat terminal discrete input, empat terminal analog input dan empat terminal output. Kebutuhan suplai tegangan Zelio (SR2B121BD) adalah 24 VDC. Output Zelio mengeluarkan tegangan 24 VDC sedangkan tegangan masukannya adalah 24 VDC (discrete input) dan 0-10 VDC untuk analog input [4].

\section{LDR (Light Dependent Resistor)}

Light Dependent Resistor (LDR) adalah resistor yang nilai hambatanya dipengaruhi oleh cahaya yang mengenainya. Resistansi LDR akan berubah seiring dengan perubahan intensitas cahaya yang mengenainya atau yang ada disekitarnya. Semakin besar cahaya yang mengenai LDR, maka semakin kecil nilai hambatan LDR. Sebaliknya, semakin kecil cahaya mengenai LDR maka semakin besar nilai hambatan LDR [5]. Gambar 2. Merupakan Grafik hubungan resistansi LDR dengan intensitas cahaya.

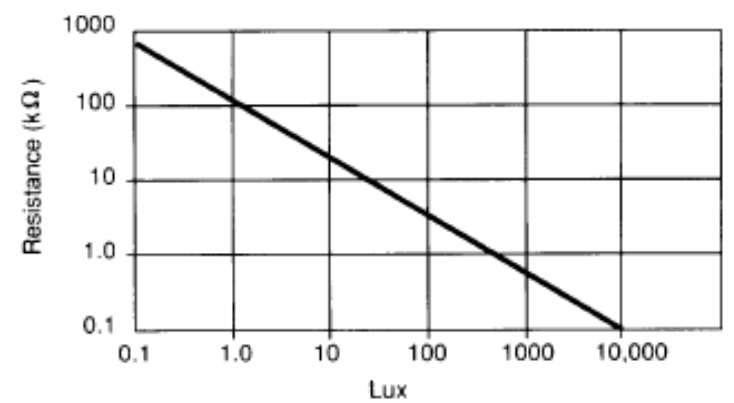

Gambar 2: Grafik hubungan resistansi LDR dengan intensitas cahaya [6]

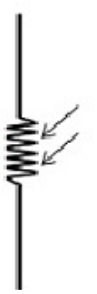

Gambar 3a: Simbol LDR

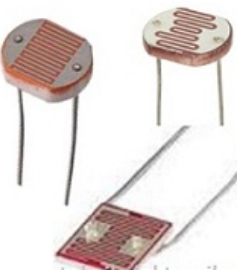

Gambar 3b: LDR
Jadi kemiringan modul surya maksimum adalah sebesar $15.12^{\circ}$.

\section{Metode Penelitian}

Penelitian dilakukan di Laboratorium Teknik Digital dan Mikroprosessor Jurusan Teknik Elektro dan Komputer Fakultas Teknik Universitas Udayana. Tahapan - tahapan dalam penelitian ini adalah perancangan hardware dan perancangan software.

\section{A. Perancangan Hardware}

Perancangan hardware pada penelitian ini meliputi perancangan wiring perangkat keras dan diagram alir (flowchart) program.
1) Perancangan wiring perangkat keras: Gambar 4 merupakan perancangan wiring perangkat keras yang dibangun pada penelitian ini.

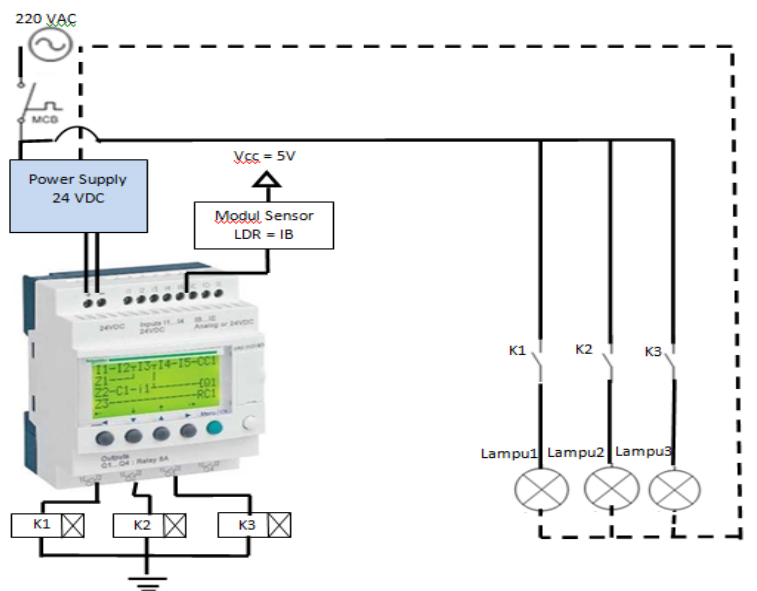

Gambar 4: Perancangan wiring perangkat keras

2) Diagram Alir (Flowchart): Gambar 5 merupakan diagram alir (flowchart) dari penelitian ini.

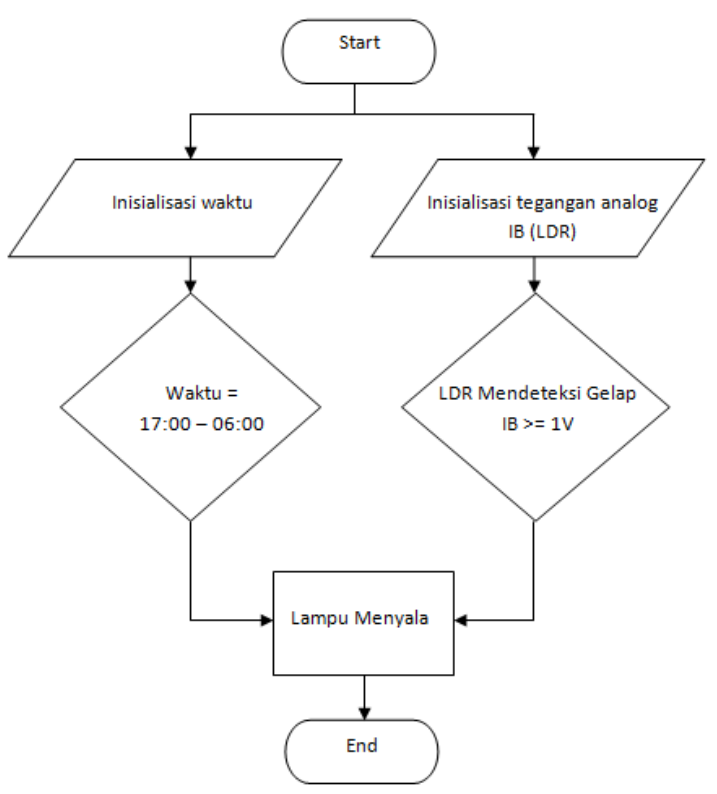

Gambar 5: Diagram alir (flowchart)

\section{B. Perancangan Software}

Perancangan software pada penelitian ini menggunakan ladder diagram pada software zeliosoft 2.0. Sebelum melakukan perancangan ladder diagram yang perlu dilakukan adalah menentukan I/O yang akan digunakan. Hal ini penting untuk integrasi pemrograman pada software dengan hardware zelio pada sistem pencahayaan. Perancangan software meliputi penentuan variabel I/O Zelio, Pemrograman diagram ladder, pengaturan fungsi Real Time Clock dan pengaturan analog input IB (Sensor LDR). 
1) Penentuan Variabel I/O Zelio: Penentuan variabel I/O zelio bertujuan untuk integrasi pemrograman pada software dengan hardware zelio pada sistem pencahayaan. Tabel 1 adalah tabel I/O yang digunakan pada rancang bangun ini.

TABEL I

I/O ZELIO

\begin{tabular}{|c|c|c|c|}
\hline NO & Input & Output & Keterangan \\
\hline 1 & IB & & Analog input modul LDR \\
\hline 2 & AI & & Analog comparator IB \\
\hline 3 & & Q1 & Relay lampu 1 \\
\cline { 1 - 1 } 4 & & Q2 & Relay lampu 2 \\
\cline { 4 - 4 } & & Q3 & Relay lampu 3 \\
\cline { 4 - 4 } & &
\end{tabular}

2) Pemrograman Diagram Ladder: Gambar 6 merupakan diagram ladder yang diprogram.

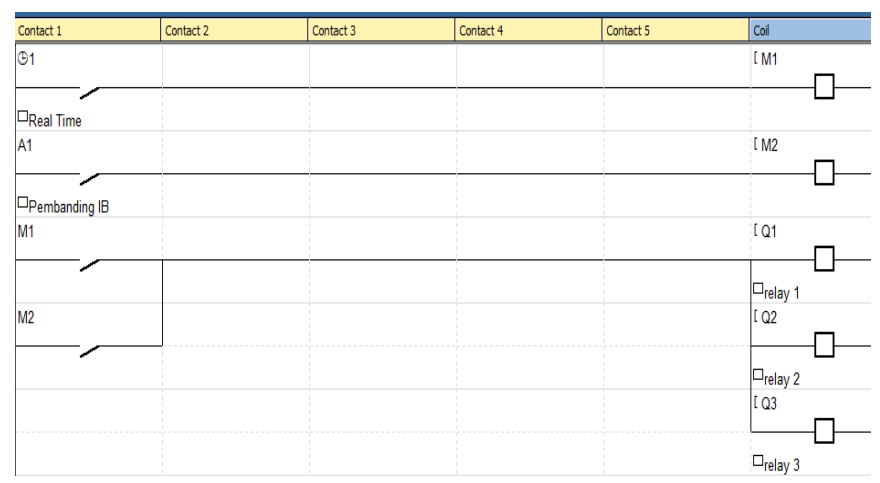

Gambar 6: Ladder diagram

3) Pengaturan Real Time Clock.: dilakukan untuk mengaktifkan sistem pencahayaan otomatis dijalankan sesuai jam dan hari yang diinginkan. Dalam rancang bangun ini waktu hidup lampu adalah setiap hari pada jam 17.00-06.00. yang disajikan pada Gambar 7.

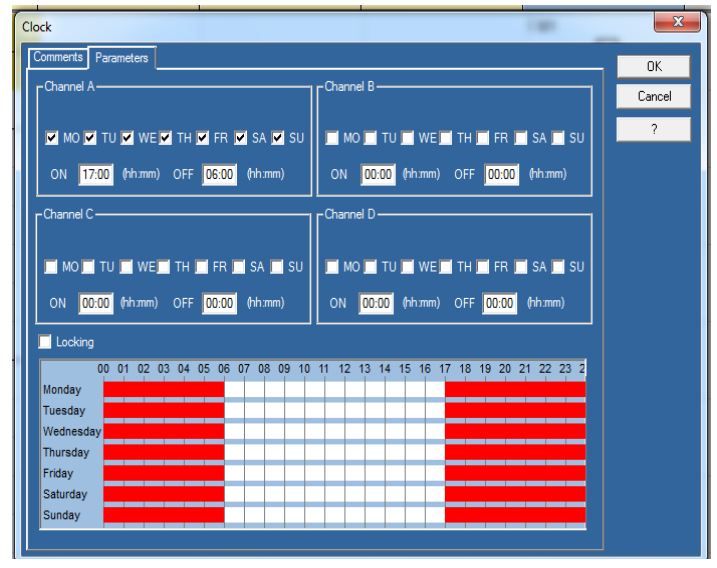

Gambar 7: Pengaturan RTC

4) Pengaturan Analog Input IB (Sensor LDR): Pengaturan analog comparator A1 bertujuan untuk mengolah tegangan analog yang dihasilkan oleh sensor LDR agar dapat diolah

Andri Ferdiansyah: Rancang Bangun Sistem Pencahayaan... menjadi masukan pada hardware zelio seperti yang disajikan pada Gambar 8 .

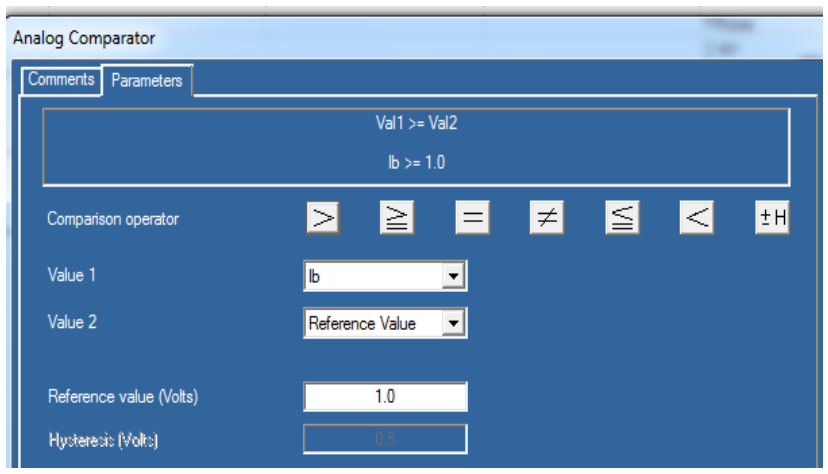

Gambar 8: Konfigurasi analog comparator A1

Gambar 8 menunjukan bahwa analog comparator A1 membandingkan nilai tegangan analog sensor LDR (IB) dengan tegangan referensi 1 VDC dan operator(>=). Artinya, kontak A1 akan aktif jika nilai tegangan sensor LDR masuk ke terminal zelio IB $>=1$ VDC.

\section{HASIL DAN PEMBAHASAN}

\section{A. Pengujian Real Time Clock}

Pengujian real time clock adalah pengujian untuk mengetahui apakah nyala output lampu sesuai pengaturan waktu yang telah ditentukan yakni jam 17:00-06:00 selama seminggu. Sampel hasil dari pengujian real time clock ditampilkan pada gambar 9-10 dan secara keseluruhan disajikan pada Tabel 2.

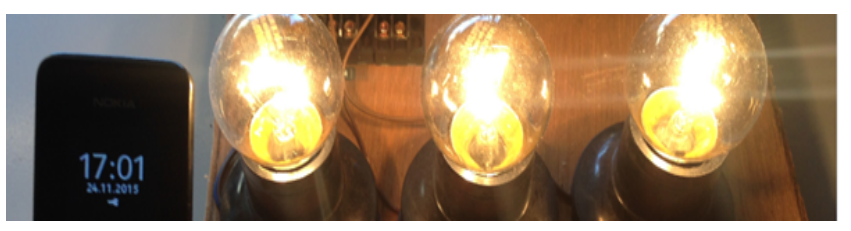

Gambar 9: Pengujian real time clock pukul 17:01

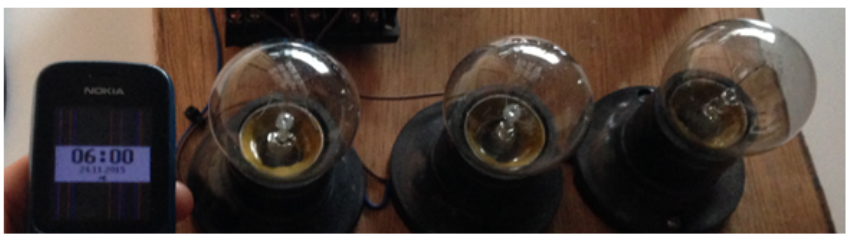

Gambar 10: Pengujian real time clock pukul 06:00

TABEL III

Hasil Pengujian Real Time CLOCK

\begin{tabular}{|c|c|c|c|}
\hline No & Hari & Pukul & Output Lampu \\
\hline 1 & Senin & $06: 00$ & Off \\
\hline 2 & Selasa & $17: 01$ & On \\
\hline 3 & Rabu & $18: 57$ & On \\
\hline 4 & Kamis & $19: 00$ & On \\
\hline 5 & Jumat & $19: 09$ & On \\
\hline
\end{tabular}

p-ISSN:1693 - 2951; e-ISSN: 2503-2372 


\begin{tabular}{|c|c|c|c|}
\hline 6 & Sabtu & $05: 50$ & On \\
\hline 7 & Minggu & $06: 01$ & Off \\
\hline
\end{tabular}

Tabel 2 menunjukkan bahwa nyala lampu penerangan yang dikontrol oleh Real Time Clock berjalan sesuai program yakni 17:00 - 06:00 selama seminggu.

\section{B. Pengujian Modul LDR}

Pengujian Modul LDR dilakukan dengan dua cara, yaitu pengujian modul LDR secara manual dan pengujian modul LDR terhadap waktu.

1) Pengujian Modul LDR Secara Manual: Pengujian modul LDR secara manual adalah pengujian dengan cara menempatkan media penghalang secara manual pada modul LDR agar modul LDR tidak mendapat cahaya (mendeteksi gelap). Pengujian modul LDR secara manual bertujuan untuk menguji apakah lampu akan hidup ketika LDR mendeteksi gelap secara manual. Hasil pengujian modul LDR secara manual ditampilkan pada gambar 11-14 dan disajikan pada Tabel 3.

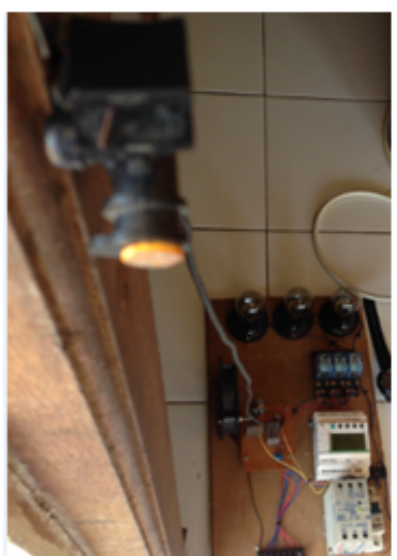

Gambar 11: Pengujian modul LDR saat kondisi normal (terang)

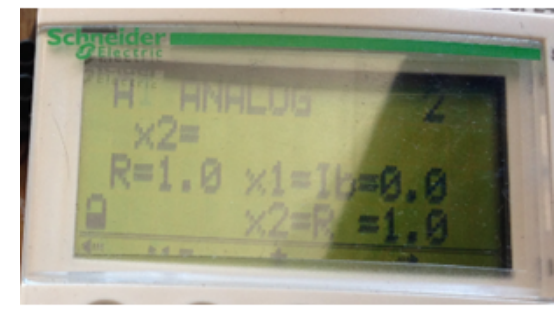

Gambar 12: Nilai Tegangan LDR yang dibaca program saat kondisi normal

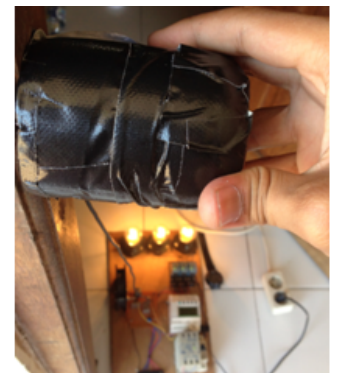

Gambar 13: Pengujian modul LDR saat sumber cahaya dihalangi (gelap)

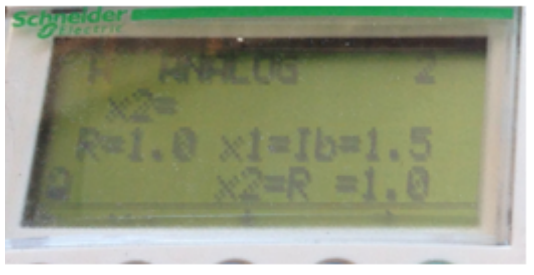

Gambar 14 Nilai Tegangan LDR yang dibaca program saat sumber cahaya dihalangi (gelap)

TABEL IIIII

HASIl PENGUJian Modul SENSOR LDR SeCARA MANuAL

\begin{tabular}{|c|c|c|c|}
\hline No & $\begin{array}{c}\text { Sumber Cahaya ke } \\
\text { LDR }\end{array}$ & $\begin{array}{c}\text { Nilai IB } \\
\text { (VDC) }\end{array}$ & $\begin{array}{c}\text { Output } \\
\text { lampu }\end{array}$ \\
\hline 1 & Dibuka & 0 & Off \\
\hline 2 & Ditutup & 1.5 & On \\
\hline
\end{tabular}

Tabel 3 menunjukkan bahwa pengujian modul LDR secara manual untuk menyalakan lampu berjalan sesuai pengaturan yang telah ditentukan pada program zelio, yaitu lampu akan menyala ketika LDR mendeteksi gelap (tegangan analog $>=1$ VDC) dan lampu tidak menyala ketika LDR mendeteksi terang (tegangan analog < 1 VDC).

2) Pengujian Modul LDR Terhadap Waktu: Pengujian modul LDR terhadap waktu adalah pengujian yang dilakukan dengan cara memberikan sumber cahaya matahari langsung pada modul LDR diluar ruangan agar modul LDR mampu merespon perubahan intensitas sumber cahaya matahari yang terpengaruh oleh waktu. Pengujian modul LDR terhadap waktu bertujuan untuk mengetahui pada jam - jam berapakah lampu akan menyala ketika LDR mendeteksi gelap. Sampel hasil dari pengujian real time clock ditampilkan pada Gambar 15-17 dan secara keseluruhan disajikan pada Tabel 4.

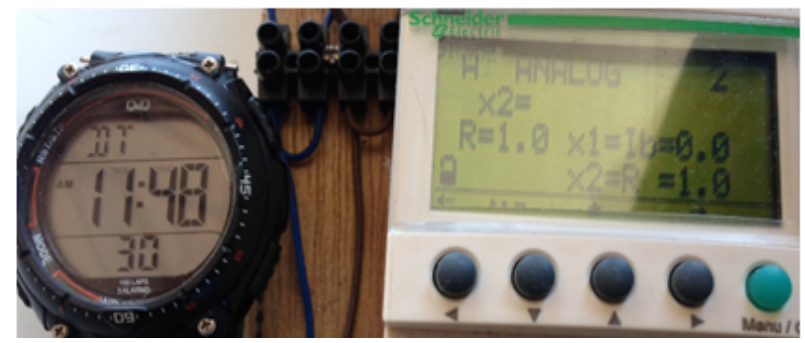

Gambar 15: Nilai Tegangan LDR yang dibaca program pukul 11:48

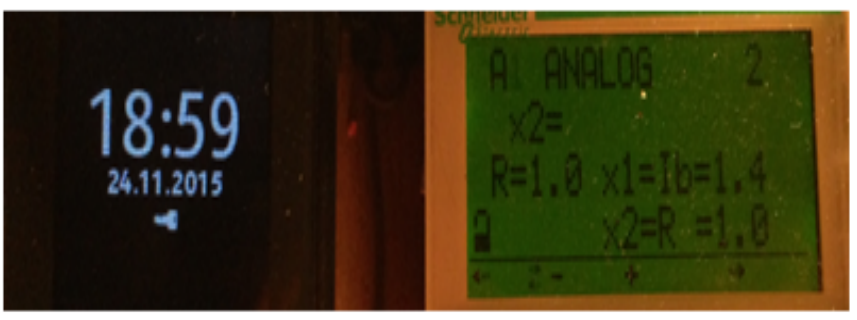

Gambar 16: Nilai Tegangan LDR yang dibaca program pukul 18:59 


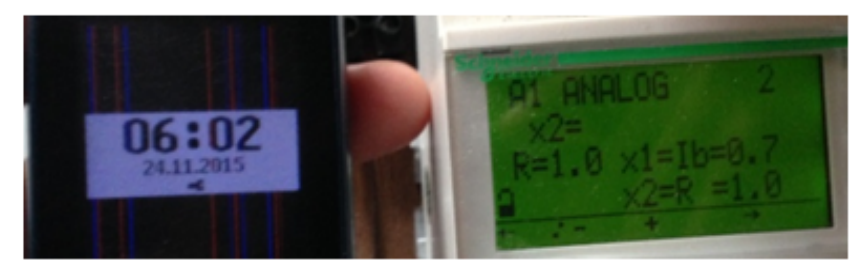

Gambar 17: Nilai Tegangan LDR yang dibaca program pukul 06:02

TABEL IVV

Hasil PenguJian MOdUl LDR TERHADAP WAKTU

\begin{tabular}{|c|c|c|c|}
\hline No & Jam & $\begin{array}{c}\text { Tegangan IB } \\
\text { (VDC) }\end{array}$ & $\begin{array}{c}\text { Output } \\
\text { lampu }\end{array}$ \\
\hline 1 & 11.48 & 0 & Off \\
\hline 2 & 16.50 & 0 & Off \\
\hline 3 & $18: 51$ & 1.3 & On \\
\hline 4 & $18: 59$ & 1.4 & On \\
\hline 5 & 06.02 & 0.7 & Off \\
\hline
\end{tabular}

Tabel 4 menunjukkan bahwa ketika di siang hari pukul 11:48, modul LDR mendeteksi (kondisi terang) dan tegangan analog yang dihasilkan oleh modul LDR $<1$ VDC sehingga lampu tidak menyala. Sedangkan menjelang malam hari pada jam 18:51, modul LDR tidak mendapat sumber cahaya matahari dan tegangan analog yang dihasilkan oleh modul LDR $>=1$ VDC sehingga lampu menyala.

\section{KESIMPULAN}

Kesimpulan dari penelitian ini adalah sebagai berikut.

1. Hidupnya lampu penerangan berhasil dikontrol oleh Real Time Clock Function pada PLC zelio setiap hari antara jam 17:00 - 06:00 atau disaat modul sensor LDR mendeteksi gelap.

2. Sistem Pencahayaan otomatis berbasis pemrograman ladder PLC Zelio telah berhasil direalisasikan.

\section{REFERENSI}

[1] Eddi Kurniawan, Cucu Suhery, Dedi Triyanto, 2013. Sistem Penerangan Rumah Otomatis Dengan Sensor Cahaya berbasis Mikrokontroller. Jurnal Coding Sistem Komputer Universitas Tanjungpura. 1(2).

[2] http://ndoware.com/kelebihan-plc.html

[3] R\&D Center. 2010. ED-4260 Programmable Logic Controller. Korea : Yong-Hoo Park.

[4] "Zelio SR2B121BD datasheet".Schneider-Electric.

[5] Supatmi,2010.Pengaruh Sensor LDR Terhadap Pengontrolan Lampu. Majalah Ilmiah Unikom.8(2).

[6] 'LDR datasheet".RS Components. USA,INC.

Andri Ferdiansyah: Rancang Bangun Sistem Pencahayaan... 
[Halaman ini sengaja dikosongkan] 